\title{
The metabolic side effects of 12 antipsychotic drugs used for the treatment of schizophrenia on glucose: a network meta-analysis
}

Yangyu Zhang ${ }^{\dagger}$, Yingyu Liu ${ }^{\dagger}$, Yingying Su, Yueyue You, Yue Ma, Guang Yang, Yan Song, Xinyu Liu, Mohan Wang, Lili Zhang and Changgui Kou*

\begin{abstract}
Background: Antipsychotics have serious metabolic side effects on blood glucose. However, the comparative influence of these drugs on blood glucose levels has not been comprehensively evaluated. We conducted a network meta-analysis to create a hierarchy of the side effects of 12 antipsychotic drugs on changes in blood glucose levels.
\end{abstract}

Methods: A systematic search of the PubMed, EMBASE and Cochrane databases (last search June 2016) was conducted to identify studies that reported randomized controlled trials (RCTs) comparing changes in blood glucose levels between patients receiving one of 12 antipsychotic drugs or a placebo for the treatment of schizophrenia or related disorders. The studies we searched were limited to those published in English. Two reviewers independently extracted data. The primary outcome of interest was changes in fasting glucose levels.

Results: We included 47 studies with 114 relevant arms. Of the antipsychotic drugs, only olanzapine was associated with significantly increased glucose levels compared to a placebo (mean difference (MD) $=3.95,95 \%$ confidence interval $(\mathrm{Cl})=0.14$ to 7.76$)$. Moreover, olanzapine was associated with a significantly greater change in the glucose levels than ziprasidone ( $M D=5.51,95 \% \mathrm{Cl}=1.62$ to 9.39$)$, lurasidone $(\mathrm{MD}=5.58,95 \% \mathrm{Cl}=0.53$ to 10.64$)$ or risperidone $(\mathrm{MD}=3.05,95 \% \mathrm{Cl}=0.87$ to 5.22 ). Ziprasidone and lurasidone were associated with minimal glucose changes compared to the other antipsychotics.

Conclusions: Olanzapine was associated with a significantly greater change in blood glucose levels than ziprasidone, lurasidone, risperidone or placebo treatment. The application of a hierarchy of glucose metabolism-related side effects may help clinicians tailor the choice of antipsychotic drug to meet the needs of individual patients.

Keywords: Antipsychotic drug, Glucose change, RCTs, Network meta-analysis

\section{Background}

Schizophrenia was ranked among the top 25 leading causes of disability worldwide in 2013 [1]. People with schizophrenia have mortality rates that are 2-3 times higher than the general population [2-4], which corresponds to a mortality gap of 10 to 20 years [5]. At least $60 \%$ of this premature mortality is due to cardiovascular

\footnotetext{
* Correspondence: koucg@jlu.edu.cn

${ }^{\dagger}$ Equal contributors

Department of Epidemiology and Biostatistics, School of Public Health, Jilin

University, Changchun, Jilin Province 130021, China
}

diseases [6]. Diabetes mellitus, which is a significant risk factor of cardiovascular diseases [7], is a group of metabolic diseases in which a person has high blood glucose [8] that is characterized by chronic hyperglycemia [9] either because the body does not produce sufficient insulin or because the cells do not respond to the insulin that is produced. Type 2 diabetes mellitus (T2DM) comprises approximately $90 \%$ of diabetes cases, with the other $10 \%$ of cases due primarily to type 1 diabetes mellitus and gestational diabetes. The T2DM rates are estimated to be 2 to 3 times higher in people with 
schizophrenia than in the general population, with a prevalence of $10 \%$ to $15 \%$ [10, 11]. Several studies have indicated a progressive relationship between hyperglycemia and the cardiovascular event risk beginning with glucose levels well below the diabetic thresholds [12-14].

Second-generation antipsychotics (SGAs) have been extensively recommended as first-line agents for the treatment of schizophrenia. However, several studies have reported the presence of alterations in glucose metabolism during treatment with SAGs, particularly clozapine and olanzapine [15-19]. Additionally, an increasing number of studies have reported an increased risk of hyperglycemia, diabetes, lipid dysregulation and ketoacidosis in patients treated with SGAs [20-22]. These serious effects have gradually raised concerns about a possible association between these metabolic effects and treatment with these drugs [23].

Large epidemiological studies have provided conflicting evidence regarding the relative risk of diabetes observed in association with the use of different antipsychotics [24-28]. Few prior meta-analyses have assessed glucose changes in association with several types of antipsychotic drugs [29-31] since such comparisons have been limited by the inadequacy of direct head-to-head comparisons of specific drugs.

Compared with traditional meta-analyses, network meta-analyses provide a statistical framework that allows the incorporation of evidence from both direct and indirect comparisons from a network of studies of different drugs to evaluate their treatment effects. Direct and indirect comparisons of the efficacies of the 12 antipsychotic drugs and the glucose intolerance of some of these drugs have been performed [32, 33]. However, a comparison of the effects of these 12 antipsychotics on changes in glucose using a network meta-analysis with relatively sufficient evidence has not been performed to date. Hence, we performed a network meta-analysis to evaluate the comparative effects of 12 antipsychotic drugs on changes in the glucose levels with the objective of providing a point of reference for treatment selection.

\section{Methods}

\section{Search strategy and selection criteria}

Two independent reviewers searched the PubMed, EMBASE and Cochrane Central Register of Controlled Trials databases to identify studies published from January 1995 to June 2016 using medical subject headings (MeSH) and free words. The MeSH terms included "schizophrenia, glucose, randomized controlled trials (RCTs), amisulpride, aripiprazole, asenapine, sertindole, clozapine, haloperidol, ziprasidone, lurasidone, olanzapine, paliperidone, quetiapine and risperidone." The search strategy was based on combining the MeSH terms for schizophrenia, glucose, the 12 types of oral antipsychotic drugs and RCTs with their free text variants (see Additional file 1 for search strategy details). Additionally, the reference lists of all eligible articles and recent systematic reviews were reviewed. We restricted the studies to those written in English.

Trials were considered eligible for inclusion if they (i) included people with schizophrenia or related disorders (defined by any diagnostic criteria) and had a duration of treatment that was no more than 1 year, (ii) compared any antipsychotic drugs with either placebo treatment or one of the other 12 antipsychotic drug monotherapies (amisulpride, aripiprazole, asenapine, sertindole, clozapine, haloperidol, ziprasidone, lurasidone, olanzapine, paliperidone, quetiapine and risperidone), (iii) reported fasting glucose as an outcome, and (iv) were RCTs. Trials were excluded if they (i) included schizophrenic patients with a concomitant medical illness, treatment resistance, or stable illness, (ii) were conducted in special populations, including patients with a mean age $\leq 14$ years, obesity or metabolic diseases, (iii) evaluated an antipsychotic treatment outside of the recommended dosage range, and (iv) were conference papers.

\section{Data extraction}

Two independent investigators (Zhang and Liu) reviewed the titles, abstracts and full articles that satisfied the inclusion criteria and independently extracted data into a predetermined database. The following information was extracted from each trial: first author's name, year of publication, study design, numbers and ages of participants, diagnosis method, treatment regimen details, and changes in fasting glucose. Disagreements were discussed between investigators until a consensus was reached. When disagreements regarding article inclusion could not be resolved, third and fourth reviewers were consulted. We assessed the risk of bias using the Cochrane risk of bias tool with a low, high, and unclear risk of bias. The risk of bias was evaluated according to the following items: sequence generation, allocation concealment, blinding method, incomplete outcome data, selective reporting and other bias.

\section{Statistical analysis}

We performed a network meta-analysis to analyze direct and indirect comparisons of the 12 different drugs and placebo treatment using a multivariate meta-analysis model with the STATA 13 statistical software (StataCorp. College Station, Texas, USA). A recent update in the multivariate meta-analysis procedure in STATA makes performing a network meta-analysis possible within a software that is frequently used for meta-analyses [34]. Forest plots were constructed using the R 3.2.3 software.

The outcome of interest was changes in glucose, which were defined as changes from baseline to endpoint. The mean glucose changes were used to compare the metabolic side effects of the 12 antipsychotic drugs and a placebo on glucose. Since these changes were continuous outcomes, 
the effect sizes were calculated as the mean differences (MDs) and 95\% confidence intervals (CIs). The difference between the drugs was considered significant when the 95\% CI for MD did not include 0 (equivalent to $P<0.05$ ). To rank the effects of the treatment regimens, we used surface under the cumulative ranking (SUCRA) probabilities [35]. The SUCRA results were expressed as percentages to compare each intervention to an imaginary intervention, which was always the best intervention without uncertainty. A SUCRA of $\mathrm{x} \%$ indicates that the intervention achieves $\mathrm{x} \%$ of the effectiveness of the imaginary intervention; thus, larger SUCRAs indicate more preferable interventions [32]. We conducted inconsistency analyses to explore differences between the direct and various indirect effect estimates for the same comparison [36]. Inconsistency between direct and indirect comparisons may indicate transitivity that is not immediately obvious [37, 38]. Moreover, we calculated the differences between the direct and indirect estimates in all closed loops, with the simplest loop considered triangular (formed by three treatments compared with one another). The inconsistency factor (IF) was used to evaluate differences between the direct and indirect estimates for each of the comparisons in the loop. Additionally, we obtained a 95\% CI and z-value for each IF [39, 40]. Notably, the IF is the logarithm of the ratio of two odds ratios (RoR) from the direct and indirect evidence in the loop, and RoR values approaching 1 indicate consistency between the two sources. Moreover, we conducted a subgroup analysis to explore the effects of duration in the short-term ( $\leq 12$ weeks) and longterm groups (>12 weeks). Furthermore, a sensitivity analysis was performed by removing studies with less than 30 participants and placebo-controlled trials. Publication bias was assessed using a comparison-adjusted funnel plot.

\section{Results}

\section{Search results}

The search strategy identified 448 studies. After a thorough review of the reference lists of all eligible articles and recent systematic reviews, we identified 13 additional studies. After excluding duplicate studies, the titles and abstracts of 327 studies were assessed; then, 97 articles were retrieved for more detailed review. Of these articles, only 47 reported the outcome of fasting glucose and had data available. The details of these 47 articles are shown in Additional file 2. Ten studies (10/47, 21.3\%) provided details about randomization methods, and 26 studies (55.3\% of all studies) were double-blind. Most studies did not describe the concealment details (see Additional file 3 for the risk of bias assessment). Within the included studies, the following treatment conditions were evaluated: placebo (10 studies), amisulpride (2 studies), aripiprazole (7 studies), asenapine (1 study), sertindole (2 studies), clozapine (6 studies), haloperidol (5 studies), ziprasidone (7 studies), lurasidone (4 studies), olanzapine
(34 studies), paliperidone (7 studies), quetiapine (8 studies) and risperidone (21 studies). Thirty-two studies were twoarm trials. Eleven studies were three-arm trials. Three studies were four-arm trials, and one study was a five-arm trial. A total of 9846 individuals (aged from 15 to 65 years) were included in this meta-analysis. The flowchart of the literature retrieval process is shown in Fig. 1.

\section{Glucose changes}

The network of direct treatment comparisons for changes in fasting glucose is shown in Fig. 2. The sizes of the node reflect the number of corresponding trials. The lines link the direct comparisons, and the thickness of the lines represents the number of trials comparing the two therapies. The network plot indicated that olanzapine was included in the largest number of comparisons, followed by risperidone. Comparisons containing asenapine and sertindole were rare, whereas comparisons containing olanzapine and risperidone were frequently identified.

We created a hierarchy of effect sizes based on the SUCRA rankings for glucose change. Figure 3 shows the fasting glucose changes identified in association with the 12 antipsychotics. We used MDs to compare differences in the reported glucose changes. Regarding side effects related to blood glucose, only olanzapine was associated with a significant increase in glucose compared to placebo treatment $(\mathrm{MD}=3.95,95 \% \mathrm{CI}=0.14$ to 7.76 ) (Fig. 4). Additionally, olanzapine was associated with a significantly greater change in glucose than ziprasidone $(\mathrm{MD}=5.51,95 \% \mathrm{CI}=1.62$ to 9.39$)$, lurasidone $(\mathrm{MD}=$ $5.58,95 \% \mathrm{CI}=0.53$ to 10.64$)$ or risperidone $(\mathrm{MD}=3.05$, $95 \% \mathrm{CI}=0.87$ to 5.22 ).

SUCRA values were used to determine the hierarchy of the antipsychotic treatments, which is shown in Fig. 4. A larger SUCRA value indicates a higher ranking for the drug. In our study, the SUCRA values indicated the following hierarchy among the 13 treatments: $69.4,52.9$, 64.4, 39.7, 28.9, 23.8, 32.0, 84.1, 82.8, 19.2, 43.2, 49.8 and $59.9 \%$ for placebo, amisulpride, aripiprazole, asenapine, sertindole, clozapine, haloperidol, ziprasidone, lurasidone, olanzapine, paliperidone, quetiapine and risperidone, respectively. These probabilities may inform the ranking of these treatments in terms of their glucose metabolism-related adverse effects.

\section{Inconsistency analysis of the obtained outcomes}

To determine potential inconsistencies between the direct and indirect comparisons, we conducted an inconsistency analysis using glucose changes as the outcome of interest. The results indicated that there was no significant difference between the direct and indirect comparisons $\left(x^{2}=37.49, P=0.16\right)$. When we used nodesplitting models, the direct and indirect comparisons 


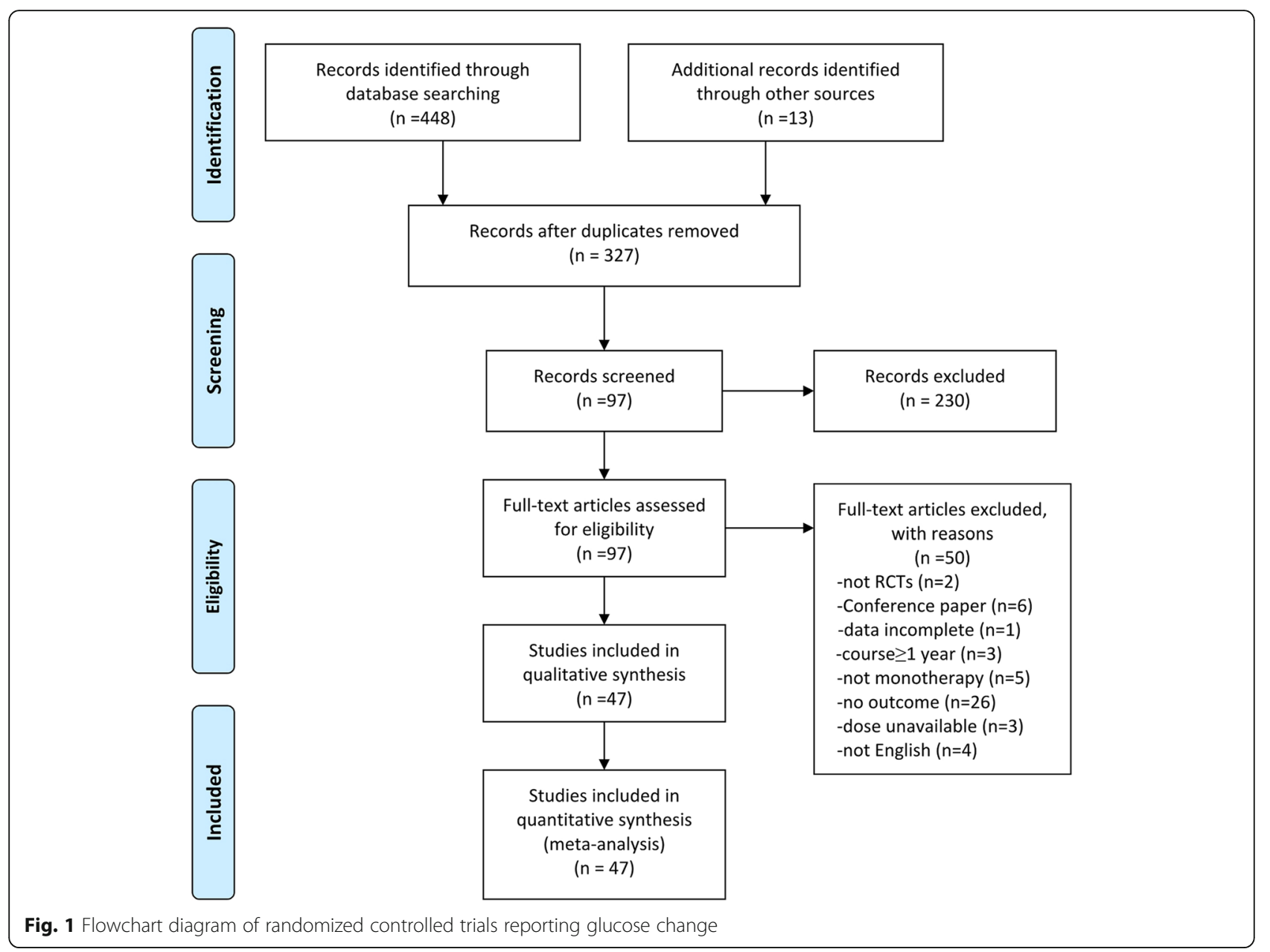

between quetiapine and aripiprazole $(P=0.036)$ seemed to be inconsistent; however, no other inconsistencies were indicated. The results also showed that no significant inconsistencies were identified in any of the 31 loops, and all of the RoRs were compatible with zero inconsistency $($ RoR $=1)$. Nevertheless, several of the loops included values with high inconsistency (mean RoR larger than 2) that indicated that the direct estimates were twice as large as the indirect estimates or vice versa. Overall, no obvious inconsistencies were identified between the direct and indirect comparisons.

\section{Subgroup and sensitivity analyses}

Through the subgroup analyses, we found some differences between short-term and long-term studies. In the shortterm studies, no significant differences were identified between any antipsychotic drugs. However, in the longterm studies, comparisons between amisulpride, asenapine, sertindole, haloperidol, olanzapine, quetiapine, risperidone, and aripiprazole and between ziprasidone and olanzapine indicated significant differences.
The sensitivity analysis indicated stable results when studies with less than 30 participants were excluded; however, when we removed placebo-controlled trials, the rankings of the glucose metabolism-related effects changed. The comparison-adjusted funnel plot was symmetric around the zero line, indicating that there was no evidence of publication bias (see Additional file 4 for the funnel plot).

\section{Discussion}

We attempted to integrate data from clinical trials as comprehensively as possible and performed an exhaustive comparison of the metabolic side effects of 12 antipsychotic drugs on blood glucose. Unlike traditional pairwise meta-analyses, network meta-analyses enable the performance of a simultaneous comparison of all included trials and can present a comprehensive and transparent picture of hierarchies among the 12 antipsychotic drugs. Network meta-analyses not only contain the outcomes of direct comparisons but also combine these results with those of indirect comparisons that are rarely reported in head-to-head RCTs, 


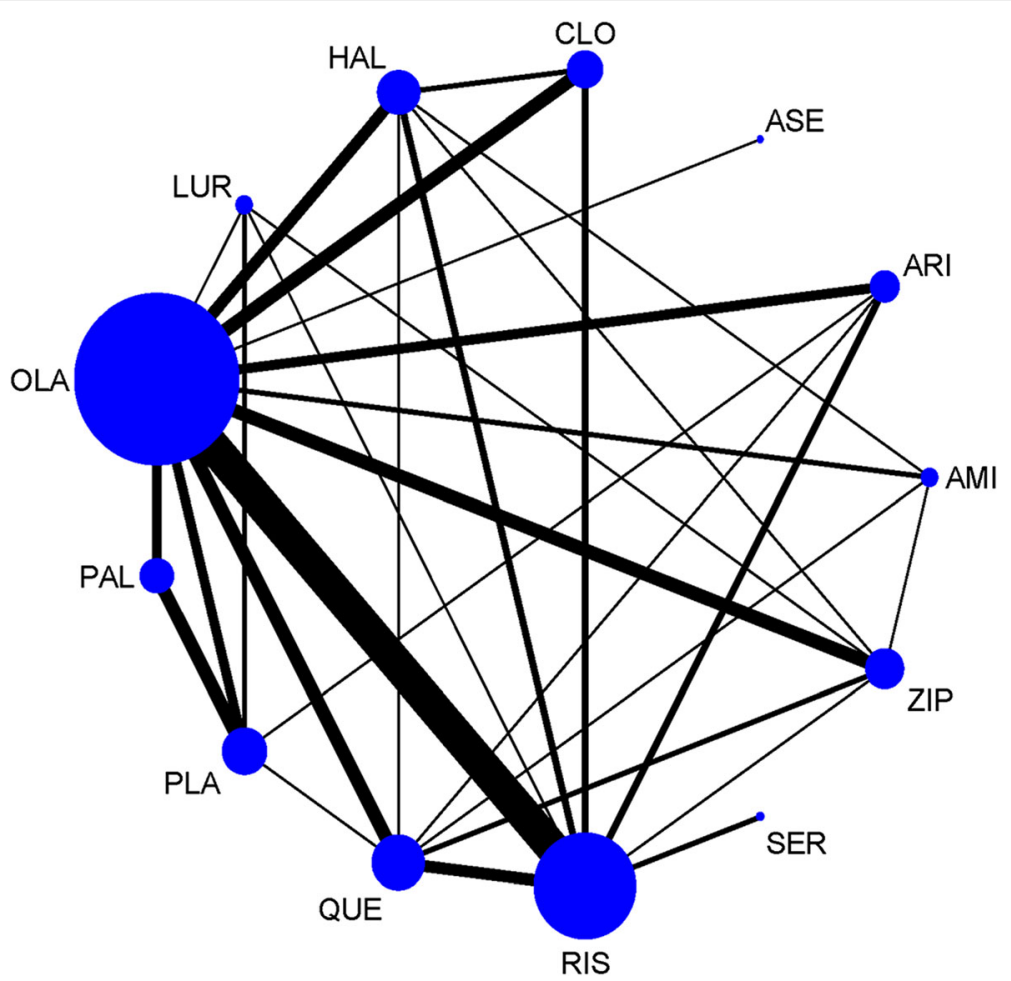

Fig. 2 Network of treatment comparisons for glucose changes. $P L A=$ placebo. $A M I=$ amisulpride. $A R I=$ aripiprazole. $A S E=$ asenapine. $C L O=c l o z a p i n e$. $\mathrm{HAL}=$ haloperidol. $\mathrm{LURA}=$ lurasidone. $\mathrm{OLA}=$ olanzapine. $\mathrm{PAL}=$ paliperidone. $\mathrm{QUE}=$ quetiapine. $\mathrm{RIS}=$ risperidone. $\mathrm{SER}=$ sertindole. $\mathrm{ZIP}=\mathrm{ziprasidone}$

presenting an advantage relative to conventional metaanalyses. We present the first study to simultaneously compare side effects related to glucose changes that occur in association with 12 antipsychotic drugs in people with schizophrenia. Our study showed that of the drug treatments for schizophrenia, only olanzapine was associated with a significant increase in glucose-related side effects compared with placebo treatment. Olanzapine was also associated with a conspicuous and significant change in glucose compared with ziprasidone, lurasidone and

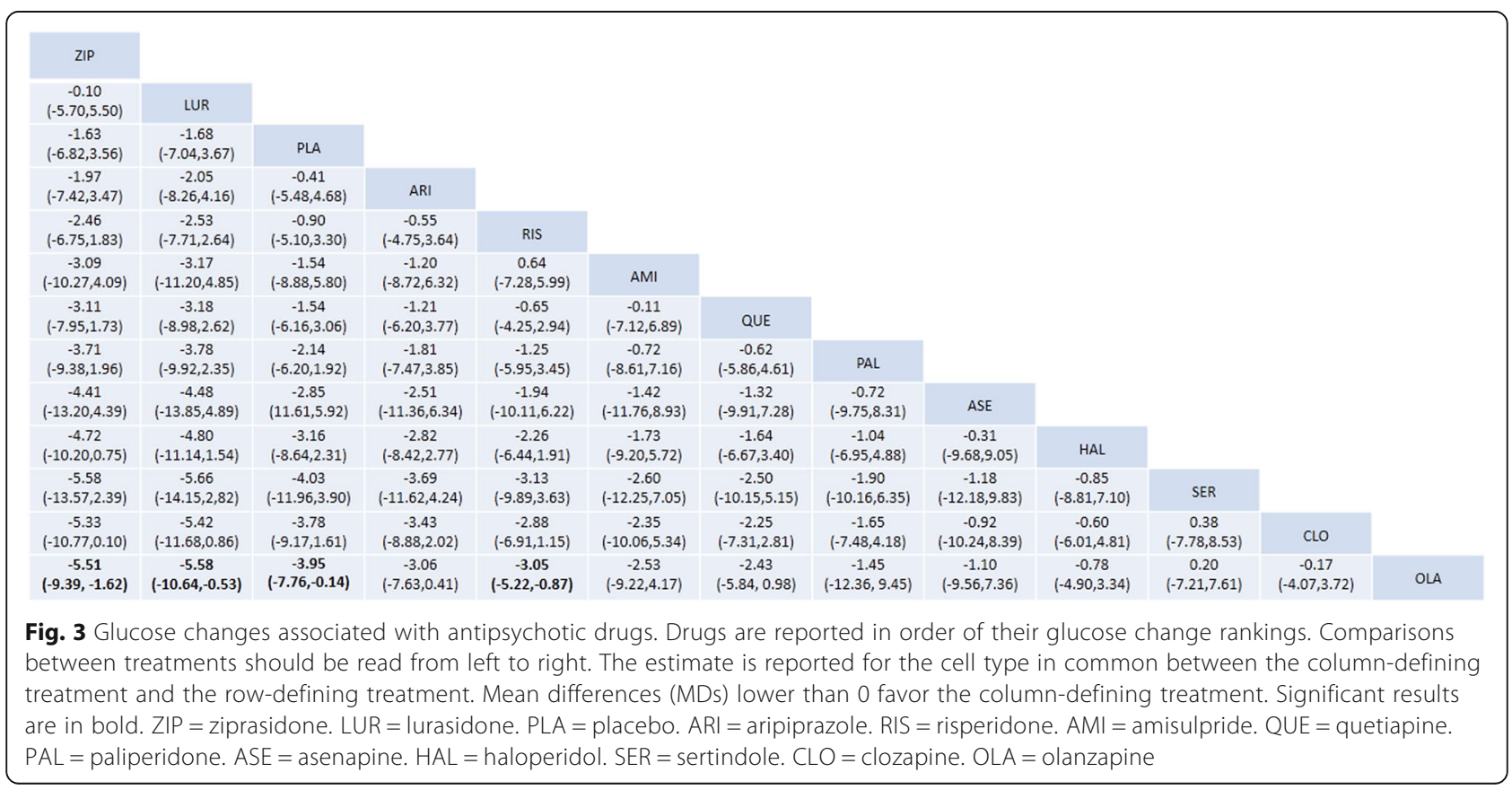




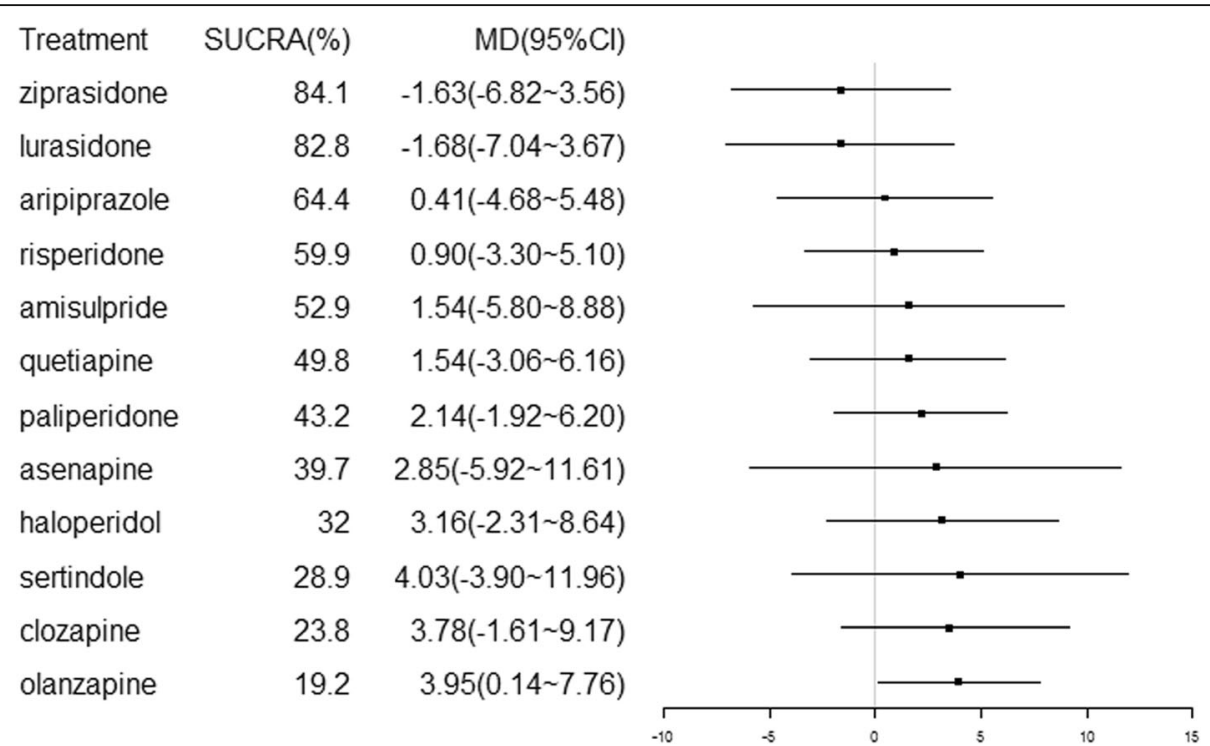

Fig. 4 Forest plot for glucose changes associated with antipsychotics drugs compared with placebo treatment. Treatments are ranked based on their surface under the cumulative ranking (SUCRA) values

risperidone. Based on the SUCRA probabilities, we created hierarchies of effect size for blood glucose metabolism. Ziprasidone and lurasidone were associated with fewer glucose-related side effects than any of the other antipsychotics and placebo treatment and were followed in ranking by aripiprazole, risperidone, amisulpride, quetiapine, paliperidone, asenapine and haloperidol. Olanzapine, clozapine and sertindole were associated with more substantial changes in the blood glucose levels.

This review strove to comprehensively and systematically review published evidence from a wide variety of sources. To minimize potential bias, two researchers independently searched and screened the literature, extracted available information and assessed the quality of the studies. The glucose concentrations evaluated in our network meta-analysis were entirely fasting glucose, and the evaluated doses of the drugs were within the specified ranges.

Hyperglycemia induced by antipsychotics was first reported in 1964 in association with phenothiazine derivatives [41]. A series of uncontrolled case reports revealed that hyperglycemia in schizophrenic patients was associated with antipsychotic treatment. After reviewing reports examining the association between hyperglycemia and diabetes and antipsychotic use, we found that associations with clozapine were identified most frequently, followed by olanzapine [25, 42-53]. A variety of published studies, including large retrospective database analyses, uncontrolled observational and controlled experimental studies, and RCTs, have reported associations between different types of atypical antipsychotics and changes in glucose levels. Although the patients treated with olanzapine and clozapine in these studies were more likely to develop diabetes, our results showed that only olanzapine was significantly associated with changes in glucose compared with placebo treatment, indicating a difference from the findings of other studies. This difference could have occurred because five of the six clozapine studies evaluated the use of shortterm therapy ( $<12$ weeks), whereas glucose levels might be more affected by long-term therapy [54]. In our study, the finding that sertindole was associated with elevated mean glucose levels was surprising; however, previous reports have also indicated small increases in glucose associated with sertindole [55] and an acceptable metabolic profile for this drug [56].

Lindenmayer et al. [57] conducted a study using modified glucose tolerance tests that showed that patients in the olanzapine-treated and clozapine-treated groups consistently exhibited significant increases in glucose levels relative to haloperidol-treated patients and untreated subjects in the control group. Reynolds et al. [58] hypothesized that SGAs might be responsible for incident diabetes cases, probably due to specific diabetogenic actions, particularly in association with drugs such as clozapine and olanzapine. However, although the first-generation antipsychotic haloperidol appeared to have less influence on glucose levels than olanzapine and clozapine in the current study, no obvious advantages were identified when haloperidol was compared to other SAGs.

Although a considerable number of studies have assessed the effect of risperidone treatment, few of these studies have identified side effects related to glucose, 


\section{Publisher's Note}

Springer Nature remains neutral with regard to jurisdictional claims in published maps and institutional affiliations.

Received: 18 April 2017 Accepted: 13 November 2017

Published online: 21 November 2017

\section{References}

1. Collaborators GBoDS. Global, regional, and national incidence, prevalence, and years lived with disability for 301 acute and chronic diseases and injuries in 188 countries, 1990-2013: a systematic analysis for the Global Burden of Disease Study 2013. Lancet. 2015;386(9995):743-800.

2. Osborn DP, Levy G, Nazareth I, Petersen I, Islam A, King MB. Relative risk of cardiovascular and cancer mortality in people with severe mental illness from the United Kingdom's general practice Rsearch database. Arch Gen Psychiatry. 2007;64(2):242-9.

3. Saha S, Chant D, McGrath J. A systematic review of mortality in schizophrenia: is the differential mortality gap worsening over time? Arch Gen Psychiatry. 2007;64(10):1123-31.

4. Reininghaus U, Dutta R, Dazzan P, Doody GA, Fearon P, Lappin J, Heslin M, Onyejiaka A, Donoghue K, Lomas B, et al. Mortality in schizophrenia and other psychoses: a 10-year follow-up of the SOP first-episode cohort. Schizophr Bull. 2015;41(3):664-73.

5. Lawrence D, Hancock KJ, Kisely S. The gap in life expectancy from preventable physical illness in psychiatric patients in Western Australia: retrospective analysis of population based registers. BMJ. 2013;346:f2539.

6. Ösby U, Correia N, Brandt L, Ekbom A, Sparén P. Mortality and causes of death in schizophrenia in Stockholm County, Sweden. Schizophr Res. 2000; 45(1-2):21-8.

7. Pocock SJ, Wang D, Pfeffer MA, Yusuf S, Mcmurray JJ, Swedberg KB, Ostergren J, Michelson EL, Pieper KS, Granger CB. Predictors of mortality and morbidity in patients with chronic heart failure. Eur Heart J. 2006;27(1):65

8. Popli AP, Konicki PE, Jurjus GJ, Fuller MA, Jaskiw GE. Clozapine and associated diabetes mellitus. J Clin Psychiatry. 1997;58(3):108.

9. Smith M, Hopkins D, Peveler RC, Holt RI, Woodward M, Ismail K. First- V. Second-generation antipsychotics and risk for diabetes in schizophrenia: systematic review and meta-analysis. Br J Psychiatry. 2008:192(6):406.

10. De Hert M, Schreurs V, Vancampfort D, Van Winkel R. Metabolic syndrome in people with schizophrenia: a review. World Psychiatry. 2009:8(1):15-22.

11. Argo T, Carnahan R, Barnett M, Holman TL, Perry PJ. Diabetes prevalence estimates in schizophrenia and risk factor assessment. Ann Clin Psych Official J Am Acad Clin Psych. 2011;23(2):117.

12. Coutinho M, Gerstein HC, Wang Y, Yusuf S. The relationship between glucose and incident cardiovascular events. A metaregression analysis of published data from 20 studies of 95,783 individuals followed for 12.4 years. Diabetes Care. 1999:22(2):233-40.

13. Cowie CC, Rust KF, Byrd Holt DD, Eberhardt MS, Flegal KM, Engelgau MM, Saydah SH, Williams DE, Geiss LS, Gregg EW. Prevalence of diabetes and impaired fasting glucose in adults in the U.S. population: National Health and Nutrition Examination Survey 1999-2002. Diabetes Care. 2006;29(6):1263.

14. Gerstein HC. Is glucose a continuous risk factor for cardiovascular mortality? Diabetes Care. 1999:22(5):659.

15. Melkersson Kl, Hulting AL, Brismar KE. Elevated levels of insulin, leptin, and blood lipids in olanzapine-treated patients with schizophrenia or related psychoses. J Clin Psychiatry. 2000;61(10):742-9.

16. Melkersson $\mathrm{Kl}$, Hulting AL. Insulin and leptin levels in patients with schizophrenia or related psychoses-a comparison between different antipsychotic agents. Psychopharmacology. 2001;154(2):205-12.

17. Wirshing DA, Boyd JA, Meng LR, Ballon JS, Marder SR, Wirshing WC. The effects of novel antipsychotics on glucose and lipid levels. J Clin Psychiatry. 2002:63(10):856-65.

18. Newcomer JW. Abnormalities of glucose metabolism associated with atypical antipsychotic drugs. J Clin Psychiatry. 2004;65(Suppl 18):36-46.

19. Ebenbichler CF, Laimer M, Eder U, Mangweth B, Weiss E, Hofer A, Hummer M, Kemmler $\mathrm{G}$, Lechleitner M, Patsch JR, et al. Olanzapine induces insulin resistance: results from a prospective study. J Clin Psychiatry. 2003;64(12):1436-9.

20. Ryan MC, Thakore JH. Physical consequences of schizophrenia and its treatment: the metabolic syndrome. Life Sci. 2002;71(3):239-57.

21. Rojo LE, Gaspar PA, Silva H, Risco L, Arena P, Cubillos-Robles K, Jara B. Metabolic syndrome and obesity among users of second generation antipsychotics: a global challenge for modern psychopharmacology Pharmacol Res. 2015:101:74-85.

22. Polcwiartek C, Vang T, Bruhn CH, Hashemi N, Rosenzweig M, Nielsen J. Diabetic ketoacidosis in patients exposed to antipsychotics: a systematic literature review and analysis of Danish adverse drug event reports. Psychopharmacology. 2016;233(21-22):3663-72.

23. Newcomer JW. Second-generation (atypical) antipsychotics and metabolic effects: a comprehensive literature review. CNS Drugs. 2005;19(Suppl 1):1-93.

24. Wilson DR, D'Souza L, Sarkar N, Newton M, Hammond C. New-onset diabetes and ketoacidosis with atypical antipsychotics. Schizophr Res. 2003; 59(1):1-6.

25. Lund BC, Perry PJ, Brooks JM, Arndt S. Clozapine use in patients with schizophrenia and the risk of diabetes, hyperlipidemia, and hypertension: a claims-based approach. Arch Gen Psychiatry. 2001;58(12):1172-6.

26. Kwong K, Hornbuckle K, Signa W, Cavazzoni P, Hutchins D. Higher incidences of diabetes mellitus during exposure to antipsychotics findings from a retrospective cohort study in the US. Eur Neuropsychopharmacol. 2001;11(01):S279-80.

27. Gianfrancesco F, Grogg A, Mahmoud R, Nasrallah H. Association of newonset diabetes and antipsychotics: findings from a large health plan database. Eur Neuropsychopharmacol. 2001:11(01):S259.

28. Buse JB, Cavazzoni P, Hornbuckle K, Hutchins D, Breier A, Jovanovic L. A retrospective cohort study of diabetes mellitus and antipsychotic treatment in the United States. J Clin Epidemiol. 2003;56(2):164-70.

29. Mitchell AJ, Vancampfort D, Sweers K, van Winkel R, Yu W, De Hert M. Prevalence of metabolic syndrome and metabolic abnormalities in schizophrenia and related disorders-a systematic review and meta-analysis. Schizophr Bull. 2013;39(2):306-18.

30. De Hert M, Yu W, Detraux J, Sweers K, van Winkel R, Correll CU. Body weight and metabolic adverse effects of asenapine, iloperidone, lurasidone and paliperidone in the treatment of schizophrenia and bipolar disorder: a systematic review and exploratory meta-analysis. CNS Drugs. 2012;26(9):733-59.

31. Rummel-Kluge C, Komossa K, Schwarz S, Hunger H, Schmid F, Lobos CA, Kissling W, Davis JM, Leucht S. Head-to-head comparisons of metabolic side effects of second generation antipsychotics in the treatment of schizophrenia: a systematic review and meta-analysis. Schizophr Res. 2010; 123(2-3):225-33.

32. Leucht S, Cipriani A, Spineli L, Mavridis D, Orey D, Richter F, Samara M, Barbui C, Engel RR, Geddes JR. Comparative efficacy and tolerability of 15 antipsychotic drugs in schizophrenia: a multiple-treatments meta-analysis. Lancet. 2013;382(9896):951-62.

33. Jiao ZY, Liang L, Teng M, Leng KA, Beng SL, Furukawa TA, Baldessarini RJ, Peng LB, Kang S. Long-term antipsychotic treatment in schizophrenia: systematic review and network meta-analysis of randomised controlled trials. Bjpsych Open. 2016:2(1):59-66.

34. Statacorp B: Stata statistical software. Release 5. 2010

35. Salanti G, Ades AE, loannidis JP. Graphical methods and numerical summaries for presenting results from multiple-treatment meta-analysis: an overview and tutorial. J Clin Epidemiol. 2011;64(2):163-71.

36. Donegan S, Williamson P, D'Alessandro U, Tudur Smith C. Assessing key assumptions of network meta-analysis: a review of methods. Res Synth Methods. 2013;4(4):291-323.

37. Caldwell DM, Gibb DM, Ades AE. Validity of indirect comparisons in meta-analysis. Cold Spring Harb Perspect Biol. 2007;369(9558):1-10.

38. Song F, Xiong T, Parekh-Bhurke S, Loke YK, Sutton AJ, Eastwood AJ, Holland R, Chen YF, Glenny AM, Deeks JJ, et al. Inconsistency between direct and indirect comparisons of competing interventions: meta-epidemiological study. BMJ. 2011;343:d4909.

39. Salanti G, Marinho V, Higgins JPT. A case study of multiple-treatments metaanalysis demonstrates that covariates should be considered. J Clin Epidemiol. 2009;62(8):857-64

40. Song F, Harvey I, Lilford R. Adjusted indirect comparison may be less biased than direct comparison for evaluating new pharmaceutical interventions - journal of clinical epidemiology. J Clin Epidemiol. 2008; 61(5):455-63.

41. Arneson GA. Phenothiazine derivatives and glucose metabolism. J NeuroOncol. 1964;5(3):181-5.

42. Ai D, Roper TA, Riley JA. Diabetic ketoacidosis and clozapine. Postgrad Med J. 1998;74(874):493-4.

43. Koval MS, Rames $\perp$, Christie $S$. Diabetic ketoacidosis associated with clozapine treatment. Diabetes Care. 1999;22(1):176-7. 
44. Kamran A, Doraiswamy PM, Jane JL, Hammett EB, Dunn L. Severe hyperglycemia associated with high doses of clozapine. Am J Psychiatry. 1994;151(9):1395.

45. Maule S, Giannella R, Lanzio M, Villari V. Diabetic ketoacidosis with clozapine treatment. Diabetes Nutr Metab. 1999;12(2):187-8.

46. Cohen D. Atypical antipsychotics and new onset diabetes mellitus: an overview of the literature. Pharmacopsychiatry. 2004;37(1):1-11.

47. Kelly DL, Conley RR, Richardson CM, Tamminga CA, Carpenter WT. Adverse effects and laboratory parameters of high-dose Olanzapine vs. Clozapine in treatment-resistant schizophrenia. Ann Clin Psychiatry. 2011;15(3-4):181-6.

48. Krakowski M, Czobor P, Citrome L. Weight gain, metabolic parameters, and the impact of race in aggressive inpatients randomized to double-blind clozapine, olanzapine or haloperidol. Schizophr Res. 2009;110(1-3):95-102.

49. Kumra S, Kranzler H, Gerbino-Rosen G, Kester HM, De Thomas C, Kafantaris V, Correll CU, Kane JM. Clozapine and "high-dose" olanzapine in refractory early-onset schizophrenia: a 12-week randomized and double-blind comparison. Biol Psychiatry. 2008;63(5):524-9.

50. Melkersson Kl. Different influences of classical antipsychotics and clozapine on glucose-insulin homeostasis in patients with schizophrenia or related psychosis. J Clin Psychiatry. 1999;60(11):783-91.

51. Bettinger TL, Mendelson SC, Dorson PG, Crismon ML. Olanzapine-induced glucose dysregulation. Ann Pharmacother. 2000;34(7-8):865-7.

52. Goldstein LE, Sporn J, Brown S, Kim H, Finkelstein J, Gaffey GK, Sachs G, Stern TA. New-onset diabetes mellitus and diabetic ketoacidosis associated with olanzapine treatment. Psychosomatics. 1999;40(5):438-43.

53. Wu RR, Zhao JP, Liu ZN, Zhai JG, Guo XF, Guo WB, Tang JS. Effects of typical and atypical antipsychotics on glucose-insulin homeostasis and lipid metabolism in first-episode schizophrenia. Psychopharmacology. 2006; 186(4):572-8.

54. Association ADAAP. Consensus development conference on antipsychotic drugs and obesity and diabetes. J Clin Psychiatry. 2004;65(2):267-72.

55. Wang SM, Han C, Lee SJ, Patkar AA, Masand PS, Pae CU. Asenapine, blonanserin, iloperidone, lurasidone, and sertindole: distinctive clinical characteristics of 5 novel atypical antipsychotics. Clin Neuropharmacol. 2013;36(6):223-38.

56. Spina E, Zoccali R. Sertindole: pharmacological and clinical profile and role in the treatment of schizophrenia. Expert Opin Drug Metab Toxicol. 2008; 4(5):629-38

57. Lindenmayer JP, Czobor P, Volavka J, Citrome L, Sheitman B, Mcevoy JP, Cooper TB, Chakos M, Lieberman JA. Changes in glucose and cholesterol levels in patients with schizophrenia treated with typical or atypical antipsychotics. Am J Psychiatry. 2003;160(2):290-6.

58. Reynolds GP, Kirk SL. Metabolic side effects of antipsychotic drug treatment - pharmacological mechanisms. Pharmacol Ther. 2010;125(1):169-79.

59. Citrome L, Cucchiaro J, Sarma K, Phillips D, Silva R, Tsuchiya S, Loebel A. Long-term safety and tolerability of lurasidone in schizophrenia: a 12-month, double-blind, active-controlled study. Int Clin Psychopharmacol. 2012;27(3):165-76.

60. Correll CU, Cucchiaro J, Silva R, Hsu J, Pikalov A, Loebel A. Long-term safety and effectiveness of lurasidone in schizophrenia: a 22-month, open-label extension study. Cns Spectrum. 2016;21(5):393-402.

61. Ketter TA, Sarma K, Silva R, Kroger H, Cucchiaro J, Loebel A. Lurasidone in the long-term treatment of patients with bipolar disorder: a 24-week open-label extension study. Depress Anxiety. 2016;33(5):424-34.

62. Meltzer HY, Cucchiaro J, Silva R, Ogasa M, Phillips D, Xu J, Kalali AH, Schweizer E, Pikalov A, Loebel A. Lurasidone in the treatment of schizophrenia: a randomized, double-blind, placebo- and Olanzapinecontrolled study. Am J Psychiatry. 2011;168(9):957-67.

63. Oh GH, Yu JC, Choi KS, Joo EJ, Jeong SH. Simultaneous comparison of efficacy and tolerability of second-generation antipsychotics in schizophrenia: mixedtreatment comparison analysis based on head-to-head trial data. Psychiatry Investigation. 2015;12(1):46-54.

\section{Submit your next manuscript to BioMed Central and we will help you at every step:}

- We accept pre-submission inquiries

- Our selector tool helps you to find the most relevant journal

- We provide round the clock customer support

- Convenient online submission

- Thorough peer review

- Inclusion in PubMed and all major indexing services

- Maximum visibility for your research

Submit your manuscript at www.biomedcentral.com/submit
Biomed Central 